\title{
Decreased Serum Concentration of Total IgG Is Related to Tumor Progression in Gastric Cancer Patients
}

\author{
Hiroaki Saito, Kozo Miyatani, Yusuke Kono, Yuki Murakami, Hirohiko Kuroda, Tomoyuki Matsunaga, Yoji \\ Fukumoto, Shuichi Takano, Tomohiro Osaki and Yoshiyuki Fujiwara
}

Division of Surgical Oncology, Department of Surgery, School of Medicine, Tottori University Faculty of Medicine, Yonago 683-8503, Japan

\begin{abstract}
Background There is accumulating evidence that shows cell-mediated immunity regulated by $\mathrm{T}$ cells is impaired in cancer patients. Unfortunately, the mechanisms by which $\mathrm{B}$ cells participate in tumor immunity are only partially understood.

Methods The serum concentration of Immunoglobulin $\mathrm{G}$ (IgG) was measured by Enzyme-Linked ImmunoSorbent Assay (ELISA) in patients with gastric cancer. Immunohistochemistry was also performed using the anti- cluster of differentiation (CD)134 antibody to evaluate the number of plasma cells in the tumor tissue.

Results The total serum IgG concentration was significantly lower in patients with lymph node metastasis compared with patients without metastasis. The serum concentration of total IgG at stage III/IV was significantly lower compared with tumors classified as stage I/II. A decreased serum concentration of total IgG and IgG1 was significantly related to a poor prognosis for gastric cancer patients. Furthermore, multivariate analysis indicated that the serum concentration of $\mathrm{IgG}$ and lymph node metastasis were independent prognostic indicators for poorer survival. The number of plasma cells was significantly lower in gastric cancer tissue compared with non-cancerous gastric mucosa.
\end{abstract}

Conclusion A decreased serum concentration of $\mathrm{IgG}$ was closely related to poor prognosis, indicating the possibility that impaired antibody-mediated immunity is associated with tumor progression in patients with gastric cancer.

Key words B cell; gastric cancer; IgG; plasma cell; prognosis

Corresponding author: Hiroaki Saito, MD, $\mathrm{PhD}$

sai10@med.tottori-u.ac.jp

Received 2017 March 27

Accepted 2017 May 1

Abbreviations: AUC, area under the curve; $\mathrm{CD}$, cluster of differentiation; CEA, carcinoembryonic antigen; CI, confidence interval; DSS, disease specific survival; ELISA, Enzyme-Linked ImmunoSorbent Assay; IgG, Immunoglobulin G; IL, Interleukin; MUC-1, mucin-1; ROC, receiver operating characteristic; Treg, Regulatory T cells
Because of the success of immune-checkpoint inhibitors in the treatment of various tumor types, ${ }^{1-3}$ such as antibodies for programmed cell death protein 1 and cytotoxic T-lymphocyte antigen-4, it is now clear that effective immunity against cancer cells can be induced in cancer patients. However, the spontaneous rejection of established cancers is rare because cancers frequently use physiological immunosuppressive mechanisms to escape host immunity, a phenomenon known as "tumor immune evasion."

The immune system can be divided into two branches, humoral immunity and cellular immunity. Numerous reports indicated that the function of $\mathrm{T}$ cells that play leading part of cell-mediated immunity is impaired by immunosuppressive cytokines including interleukin (IL)10 and transforming growth factor-beta by cancer cells and cancer stromal cells, ${ }^{4}$ and up-regulation of immune checkpoint molecules such as programmed cell death-1 and $\mathrm{T}$ cell immunoglobulin and mucin domain-3., 6 Regulatory T cells (Treg), described as cluster of differentiation (CD) 4+CD25+Foxp3+ cells and constituting around $10 \%$ of peripheral CD4+ T cells, are crucial for maintaining immune self-tolerance and homeostasis, and are also involved in dysfunctional T cells. ${ }^{7} 8$ Regulatory $\mathrm{T}$ cell populations are increased in the blood and tumor tissue of cancer patients and are closely correlated with the progression of various types of cancer via immunosuppression. ${ }^{9-11}$

B lymphocytes are important in adaptive immunity and antibody-mediated immune response. B cells respond to a variety of stimuli that cause them to differentiate, undergo class switching, and produce antibodies of specific classes and subclasses. Human B cells are known to produce four subclasses of Immunoglobulin $\mathrm{G}(\mathrm{IgG})$ - IgG1, IgG2, IgG3, and IgG4 — with each subclass having a different biological function. ${ }^{12}$ In healthy adult blood serum, IgG1, IgG2, IgG3, and IgG4 represent $65,25,6$, and $4 \%$ of the total IgG, respectively, but these ratios may be altered by certain diseases. ${ }^{13}$ The antibody types vary in their ability to activate immune system components, including the formation of complementary complexes or the engagement of Fc receptors 
on the surface of effector cells. ${ }^{14}$ In contrast to T cells, the mechanisms by which B cells participate in tumor immunity are only partially understood. ${ }^{15}$

Gastric cancer is one of the most common cancers in Asia and has the second highest mortality rate among all cancers worldwide. ${ }^{16}$ Despite the expression of tumor rejection antigens, such as melanoma antigens $1-3^{17}$ and the presence of tumor-specific cytotoxic T cells, ${ }^{18}$ the immune system fails to provide an adequate immune response to gastric carcinoma cells, which is similar to findings for other cancers. However, the mechanisms by which gastric cancer cells overcome antitumor immunological responses are poorly understood. Recently, some antibody drugs have been shown to be effective in the treatment of gastric cancer, indicating that antibody-mediated immunity is effective in the treatment of gastric cancer; however, little is known about humoral immunity in gastric cancer patients. This study sought to determine the serum concentration of total $\mathrm{IgG}$ and the concentration of the IgG subtypes in gastric cancer patients. From this we evaluated the relationship between IgG concentration and cancer progression to determine the status of antibody-mediated immunity in patients with gastric cancer.

\section{MATERIALS AND METHODS}

\section{Patients and normal donors}

This study enrolled 100 patients who were pathologically diagnosed with gastric adenocarcinoma and treated at Tottori University Hospital. None of the patients received radiotherapy, chemotherapy, or other medical interventions before surgery. Healthy control patients for Enzyme-Linked ImmunoSorbent Assay (ELISA) included 27 age-matched subjects (18 men and nine women; mean age $67.2 \pm 10.3$ years). There was no patient with autoimmune disease included in the current study. Institutional review board approval was obtained and all patients provided informed consent for blood and tissue donations (IRB approval number: 2675). Clinicopathological findings were generally determined according to the $14^{\text {th }}$ edition of the Japanese Classification of Gastric Carcinoma. ${ }^{19}$

\section{Measurement of serum IgG}

Serum samples were collected from the patients prior to and 1 month after their operations. The concentrations of $\mathrm{IgG}, \mathrm{IgG} 1, \mathrm{IgG} 2, \mathrm{IgG} 3$, and $\mathrm{IgG} 4$ were measured by ELISA using human IgG, IgG1, IgG2, IgG3, and IgG4 platinum ELISA kits, respectively (eBioscience, San Diego, CA).

\section{Immunohistochemistry}

Immunohistochemistry was performed in 73 patients. Tissue samples were fixed in formalin and embedded in paraffin. Serial sections were cut at $4 \mu \mathrm{m}$, dewaxed, deparaffinized in xylene, and rehydrated through a graded alcohol series. For retrieval of CD138, the sections were boiled using a microwave oven in citrate buffer $(\mathrm{pH} 9.0)$ for $15 \mathrm{~min}$. The samples were incubated in $3 \%$ hydrogen peroxidase for $10 \mathrm{~min}$ to block endogenous peroxidases, and in Block Ace (DS Pharma Biomedical, Osaka, Japan) for $20 \mathrm{~min}$ to prevent non-specific antigen binding. The slides were subsequently incubated with mouse monoclonal anti-CD138 (Nichirei, Tokyo, Japan) for $1 \mathrm{~h}$ at room temperature. Secondary antibody binding was detected with Histofine MAX-PO (Nichirei). The sections were developed using a Histofine DAB solution (Nichirei) and counterstained with Mayer's hematoxylin. Each slide was dehydrated through a graded alcohol series and covered with a coverslip. The presence of cells positive for CD138 on each slide was determined in a blinded method. Cells in parts of both non-cancerous mucosa and tumor where CD138-positive cells were observed most frequently were counted in a $\times 400$ high-power field.

\section{Statistical analysis}

Differences between the groups were analyzed using paired $t$ tests or Mann-Whitney $U$ tests. Disease specific survival (DSS) was calculated according to the KaplanMeier method and compared using the log-rank test. Patients who died of causes other than gastric cancer were considered lost to follow-up at the time of death. The Youden index was calculated using receiver operating characteristic (ROC) analysis to determine an optimal cutoff value for the concentration of IgG in evaluating survival analysis. Multivariate analysis of factors prognostic of DSS was performed using Cox's proportional hazards model and a stepwise procedure. Statistical significance was defined as $P<0.05$. Statistical analyses were performed using GraphPad Prism (GraphPad Software, La Jolla, CA) and Stat View 5.0 for Windows (SAS Institute, Cary, NC) software.

\section{RESULTS \\ Serum concentration of IgG and patient clinico- pathologic characteristics}

We first determined the serum concentration of total $\mathrm{IgG}$ and the concentration of each IgG subclass in both control and gastric cancer patients. The serum concentration of total $\mathrm{IgG}$ in gastric cancer patients was significantly lower compared with the control patients $(P=0.032$; Table 1). For the concentrations of the $\operatorname{IgG}$ subclasses, the 
serum concentration of IgG3 in gastric cancer patients tended to be lower when compared with the control patients $(P=0.082$; Table 1). The serum concentrations of $\mathrm{IgG1}, \mathrm{IgG} 2$, and IgG4 in the gastric cancer patients were lower compared with the control patients, but the differences were not statistically significant.

With regard to the correlation between serum concentration of IgG and clinicopathologic factors, the total serum concentration of IgG was significantly lower in
Table 1. Serum concentration of total IgG, IgG1, IgG2, IgG3, and IgG4 in control and gastric cancer patients

\begin{tabular}{lccl}
\hline & Control & $\begin{array}{l}\text { Gastric cancer } \\
\text { patients }\end{array}$ & $P$ value \\
\hline Total IgG & $1037 \pm 293.3$ & $905.1 \pm 412.2$ & 0.032 \\
IgG1 & $588.5 \pm 318.9$ & $539.8 \pm 397.6$ & 0.29 \\
IgG2 & $281.4 \pm 139.9$ & $248.3 \pm 141.9$ & 0.21 \\
IgG3 & $41.9 \pm 31.6$ & $32.6 \pm 26.3$ & 0.082 \\
IgG4 & $90.2 \pm 65.2$ & $84.3 \pm 80.2$ & 0.38 \\
\hline
\end{tabular}

All results expressed as means $\pm \mathrm{SD}$. IgG, Immunoglobulin G.

Table 2. Relationship between the serum concentration of each IgG subclass and the clinicopathological variables of the gastric cancer patients

\begin{tabular}{|c|c|c|c|c|c|c|c|c|c|c|}
\hline Variables & Total IgG & $P$ value & IgG1 & $P$ value & $\operatorname{IgG} 2$ & $P$ value & IgG3 & $P$ value & IgG4 & $P$ value \\
\hline Age (years) & & 0.32 & & 0.61 & & 0.59 & & 0.30 & & 0.078 \\
\hline$<70(n=59)$ & $872.7 \pm 401.9$ & & $529.6 \pm 408.4$ & & $241.6 \pm 136.8$ & & $32.8 \pm 20.9$ & & $68.8 \pm 62.3$ & \\
\hline$\geq 70(n=41)$ & $951.6 \pm 427.3$ & & $554.5 \pm 386.1$ & & $258.0 \pm 150.1$ & & $32.4 \pm 32.8$ & & $106.8 \pm 97.0$ & \\
\hline Gender & & 0.71 & & 0.87 & & 0.56 & & 0.38 & & 0.81 \\
\hline Male $(n=76)$ & $908.4 \pm 447.9$ & & $537.8 \pm 424.1$ & & $255.9 \pm 128.2$ & & $32.4 \pm 17.5$ & & $82.2 \pm 84.3$ & \\
\hline Female $(n=24)$ & $904.0 \pm 403.5$ & & $540.4 \pm 391.8$ & & $245.9 \pm 146.6$ & & $32.7 \pm 28.6$ & & $85.0 \pm 79.4$ & \\
\hline Depth of invasion* & & 0.20 & & 0.64 & & 0.26 & & 0.64 & & 0.48 \\
\hline $\mathrm{T} 1$ (early) $(n=61)$ & $958.2 \pm 441.9$ & & $567.8 \pm 433.9$ & & $266.7 \pm 159.2$ & & $31.3 \pm 26.6$ & & $92.5 \pm 88.6$ & \\
\hline $\mathrm{T} 2 / 3 / 4$ (advanced) $(n=31)$ & $821.9 \pm 333.7$ & & $496.0 \pm 350.4$ & & $219.5 \pm 105.1$ & & $34.8 \pm 25.9$ & & $71.6 \pm 64.0$ & \\
\hline Lymph node metastasis & & 0.025 & & 0.096 & & 0.31 & & 0.39 & & 0.92 \\
\hline Absent $(n=67)$ & $979.5 \pm 441.8$ & & $599.2 \pm 439.6$ & & $261.3 \pm 153.9$ & & $31.8 \pm 20.1$ & & $87.2 \pm 84.7$ & \\
\hline Present $(n=33)$ & $754.0 \pm 296.6$ & & $419.2 \pm 261.1$ & & $221.8 \pm 111.0$ & & $34.4 \pm 36.0$ & & $78.6 \pm 70.9$ & \\
\hline Histology $\dagger$ & & 0.88 & & 0.70 & & 0.14 & & 0.87 & & 0.94 \\
\hline Differentiated $(n=55)$ & $885.8 \pm 397.8$ & & $536.8 \pm 367.6$ & & $233.9 \pm 145.4$ & & $32.0 \pm 27.7$ & & $83.1 \pm 71.8$ & \\
\hline Undifferentiated $(n=45)$ & $928.6 \pm 432.6$ & & $543.5 \pm 435.7$ & & $265.9 \pm 137.0$ & & $33.4 \pm 24.7$ & & $85.8 \pm 90.2$ & \\
\hline Lymphatic involvement & & 0.94 & & 0.25 & & 0.47 & & 0.46 & & 0.39 \\
\hline Absent $(n=43)$ & $924.4 \pm 467.8$ & & $529.5 \pm 467.3$ & & $273.3 \pm 176.7$ & & $32.1 \pm 30.3$ & & $89.4 \pm 72.0$ & \\
\hline Present $(n=57)$ & $890.5 \pm 368.5$ & & $547.5 \pm 340.0$ & & $229.4 \pm 106.4$ & & $33.1 \pm 23.0$ & & $80.5 \pm 86.3$ & \\
\hline Vascular involvement & & 0.63 & & 0.84 & & 0.68 & & 0.29 & & 0.28 \\
\hline Absent $(n=57)$ & $930.1 \pm 431.7$ & & $550.0 \pm 434.8$ & & $262.1 \pm 166.0$ & & $30.8 \pm 27.6$ & & $87.1 \pm 69.4$ & \\
\hline Present $(n=43)$ & $871.9 \pm 387.4$ & & $526.2 \pm 346.7$ & & $230.0 \pm 100.5$ & & $35.1 \pm 24.5$ & & $80.6 \pm 93.3$ & \\
\hline Stage of disease & & 0.0085 & & 0.074 & & 0.47 & & 0.066 & & 0.30 \\
\hline I / II $(n=74)$ & $970.3 \pm 431.3$ & & $587.8 \pm 425.0$ & & $257.8 \pm 153.1$ & & $34.1 \pm 26.6$ & & $90.6 \pm 84.3$ & \\
\hline III / IV $(n=26)$ & $719.3 \pm 285.0$ & & $403.1 \pm 269.1$ & & $221.2 \pm 101.2$ & & $28.6 \pm 25.2$ & & $66.5 \pm 65.2$ & \\
\hline Serum albumin level & & 0.27 & & 0.56 & & 0.87 & & 0.97 & & 0.25 \\
\hline$\geq 4 \mathrm{~g} / \mathrm{dL}(n=48)$ & $929.5 \pm 394.2$ & & $560.8 \pm 393.8$ & & $247.2 \pm 150.8$ & & $35.1 \pm 31.8$ & & $86.5 \pm 65.8$ & \\
\hline$<4 \mathrm{~g} / \mathrm{dL}(n=52)$ & $882.5 \pm 430.8$ & & $520.4 \pm 404.0$ & & $249.3 \pm 134.6$ & & $30.4 \pm 19.8$ & & $82.3 \pm 92.1$ & \\
\hline Total lymphocyte count & & & & 0.14 & & 0.066 & & 0.32 & & 0.13 \\
\hline$\geq 1671(n=44)$ & $866.5 \pm 385.8$ & & $480.0 \pm 375.3$ & & $280.7 \pm 155.6$ & & $30.9 \pm 29.1$ & & $74.9 \pm 86.5$ & \\
\hline$<1671(n=56)$ & $935.4 \pm 432.9$ & & $586.8 \pm 411.5$ & & $222.8 \pm 125.6$ & & $34.0 \pm 24.0$ & & $91.8 \pm 74.7$ & \\
\hline
\end{tabular}

All results expressed as means $\pm \mathrm{SD}$.

*Depth of invasion: T1, tumor invasion of the lamina propria or submucosa; T2, tumor invasion of the muscularis propria; T3, tumor invasion of the subserosa; T4, tumor penetration of the serosa or tumor invasion of adjacent organs.

$\dagger$ Histology: Differentiated, papillary or tubular adenocarcinoma; undifferentiated, poorly differentiated or mucinous adenocarcinoma, or signet ring cell carcinoma.

IgG, Immunoglobulin G. 


\begin{tabular}{|c|c|c|c|}
\hline IgG subclass & Preoperative & Postoperative & $P$ value \\
\hline Total IgG & $991.0 \pm 419.0$ & $1071.0 \pm 417.0$ & 0.047 \\
\hline IgG1 & $605.3 \pm 417.1$ & $672.0 \pm 417.1$ & 0.04 \\
\hline $\operatorname{IgG} 2$ & $259.4 \pm 154.3$ & $245.6 \pm 164.6$ & 0.37 \\
\hline IgG3 & $33.8 \pm 28.7$ & $36.3 \pm 25.9$ & 0.33 \\
\hline IgG4 & $92.6 \pm 85.7$ & $121.6 \pm 96.6$ & $<0.0001$ \\
\hline
\end{tabular}

All results expressed as means \pm SD. IgG, Immunoglobulin G.
Table 4. Association of various factors with disease-specific survival determined by Cox's proportional hazards model and a stepwise procedure

\begin{tabular}{lllc}
\hline & HR & $95 \%$ CI & $P$ value \\
\hline $\mathrm{N}(\mathrm{n} 0-\mathrm{n} 3)^{*}$ & 3.253 & $1.995-5.305$ & $<0.0001$ \\
Total IgG (high vs low) & 0.3 & $0.093-0.967$ & 0.044 \\
\hline
\end{tabular}

$*_{n} 0$, no regional lymph node metastasis; $\mathrm{n} 1$, metastasis in $1-2$ regional lymph nodes; $\mathrm{n} 2$, metastasis in 3-6 regional lymph nodes; $\mathrm{n} 3$, metastasis in 7 or more regional lymph nodes.

CI, confidence interval; HR, hazard ratio; IgG, Immunoglobulin G.
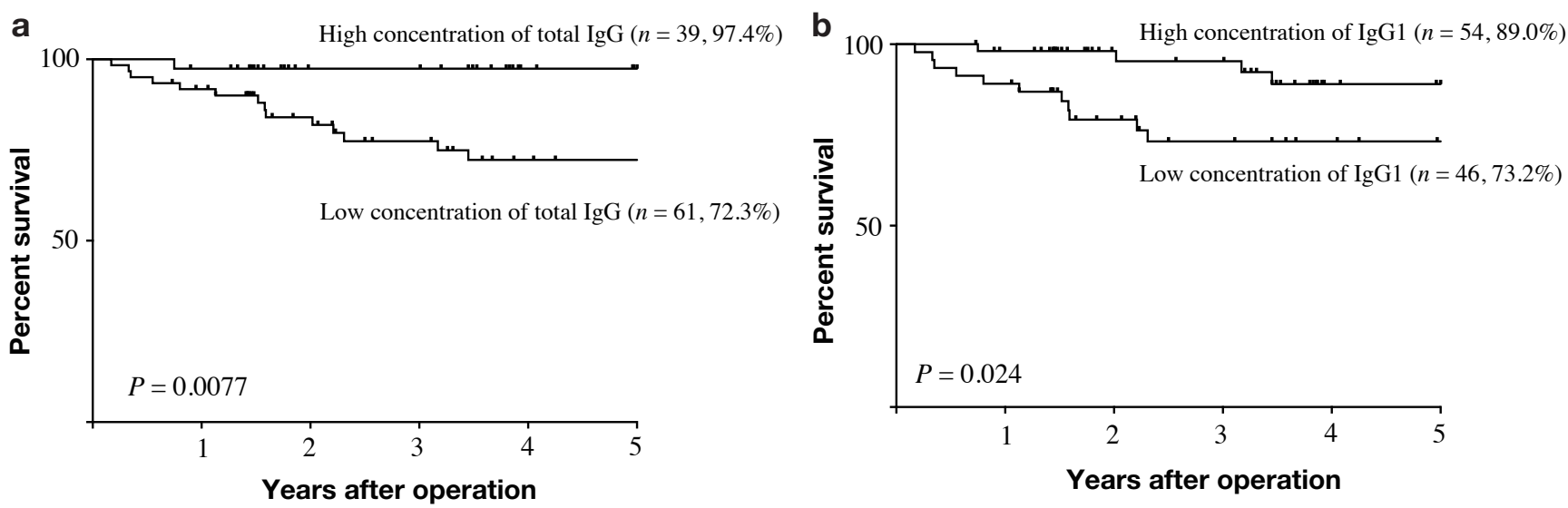

Fig. 1. Kaplan-Meier analysis of the effects of serum concentration of IgG on DSS in patients with gastric cancer. (a) The 5-year DSS rate was significantly lower in patients with low serum concentration of total IgG than those with a high serum concentration of total IgG (72.3\% vs. 97.4\%, $P=0.0077$ ). (b) The 5-year DSS rate was significantly lower in patients with a low serum concentration of total IgG1 than those with a high serum concentration of total IgG1 (73.2\% vs. 89.0\%, $P=0.024)$. DSS, disease-specific survival; IgG, Immunoglobulin G.

patients with lymph node metastasis when compared with patients without lymph node metastasis $(P=0.025$; Table 2). Serum concentration of IgG1 tended to be lower in patients with lymph node metastasis than in those without lymph node metastasis $(P=0.096$; Table 2). Furthermore, the total serum concentration of $\mathrm{IgG}$ in patients with stage III/IV tumors was significantly lower when compared with patients with stage I/II tumors $(P=$ 0.0085; Table 2). The serum concentrations of IgG1 and IgG3 in stage III/IV patients tended to be lower when compared with stage I/II patients (Table 2).

\section{Serum concentration of IgG before and after the patient's operation}

We then determined the serum concentration of $\operatorname{IgG} 1$ month after each patient's operation (Table 3). Postoperative serum concentrations of total IgG, IgG1, and $\mathrm{IgG} 4$ were significantly higher than preoperative serum concentrations of total IgG, IgG1, and IgG4, respectively.

\section{Serum concentration of $\operatorname{IgG}$ and prognosis}

Finally, we evaluated the correlation between $\operatorname{IgG}$ serum concentration and the prognosis of the gastric cancer patients. To determine an optimal cutoff value, we applied ROC analysis and used the serum concentration that had the highest Youden index (sensitivity + specificity - 1) as the optimal cutoff value. Optimal cutoff values were 933.4 [area under the curve (AUC) $0.715,95 \%$ confidence interval (CI) 0.579-0.851], 422.6 (AUC 0.654, 95\% CI 0.512-0.796), 202.4 (AUC 0.619, 95\% CI 0.4780.759 ), 32.15 (AUC $0.545,95 \%$ CI $0.391-0.699$ ), and 122.1 (AUC 0.593, 95\% CI 0.469-0.716) for total IgG, IgG1, IgG2, IgG3, and IgG4, respectively. Using these cutoffs, the 100 patients were classified into two groups: a high-concentration group, $\geq$ optimal cutoff value, and a low-concentration group, < optimal cutoff value. The 5-year DSS rates were $97.4 \%$ and $72.3 \%$ in patients with high or low concentrations of total $\mathrm{IgG}$, respectively, and the differences were statistically significant $(P<$ 0.0077 , Fig. 1a). The 5-year DSS rates were $89.0 \%$ and $73.2 \%$ in patients with a high or low concentration of 
IgG1, respectively, with the differences being statistically significant $(P=0.024$, Fig. 1b). 5-year DSS rates were $88.3 \%$ and $71.3 \%, 91.9 \%$ and $74.2 \%, 90.0 \%$ and $78.1 \%$ in patients with a high or low concentration of IgG2, IgG3, and IgG4, respectively. Although there was not a statistically significant difference for $\operatorname{IgG} 2(P=0.13), \operatorname{IgG} 3(P$ $=0.11)$, and $\operatorname{IgG} 4(P=0.088)$, the prognosis of patients with a high concentration of these IgGs was better when compared with patients with low IgG2, IgG3, and IgG4 concentrations. Because only IgG1 was significantly related to prognosis of gastric cancer patient among four subclasses of IgG, we determined the prognostic significance of IgG1 to total IgG ratio. ROC analysis indicated that AUC of IgG1 to total $\mathrm{IgG}$ ratio was 0.58 , which was lower than that of serum concentration of IgG1, showing that serum concentration of $\mathrm{IgG1}$ is more useful than IgG1 to total $\mathrm{IgG}$ ratio to predict accurate prognosis of gastric cancer patients. Using Cox's proportional hazards model and a stepwise procedure, we found that the serum concentration of total IgG and lymph node metastasis were independently prognostic for poorer survival (Table 4).

\section{The correlation between serum concentration of total IgG and CEA}

The carcinoembryonic antigen (CEA) is the tumor marker that is the most frequently used for gastric cancer patients. The 5-year survival rates of patients with either high CEA $(\geq 5 \mathrm{ng} / \mathrm{mL})$ or normal CEA $(<5 \mathrm{ng} / \mathrm{mL})$ were $43.8 \%(n=22)$ and $93.6 \%(n=78)$, respectively, and the difference was statistically significant $(P<0.0001)$. We determined the correlation between CEA and total IgG serum concentration and found that there is no correlation between serum concentration of total IgG and CEA $(r=-0.065, P=0.53$, Fig. 2).

\section{The presence of CD138-positive plasma cells in the tissue of gastric cancer}

Finally, we determined the number of plasma cells, defined as CD138-positive cells, in the tissue of non-cancerous gastric mucosa and the gastric cancers. The number of plasma cells were $106.5 \pm 54.4$ and $85.9 \pm$ 51.5 in normal gastric mucosa and gastric cancer tissue, respectively. The number of plasma cells was significantly lower in gastric cancer tissue when compared with non-cancerous gastric mucosa $(P=0.0079)$.

\section{DISCUSSION}

This study has shown that the serum concentration of total IgG was significantly lower in gastric cancer patients compared with control patients. For all subclasses of IgG, their concentrations were also lower in gastric

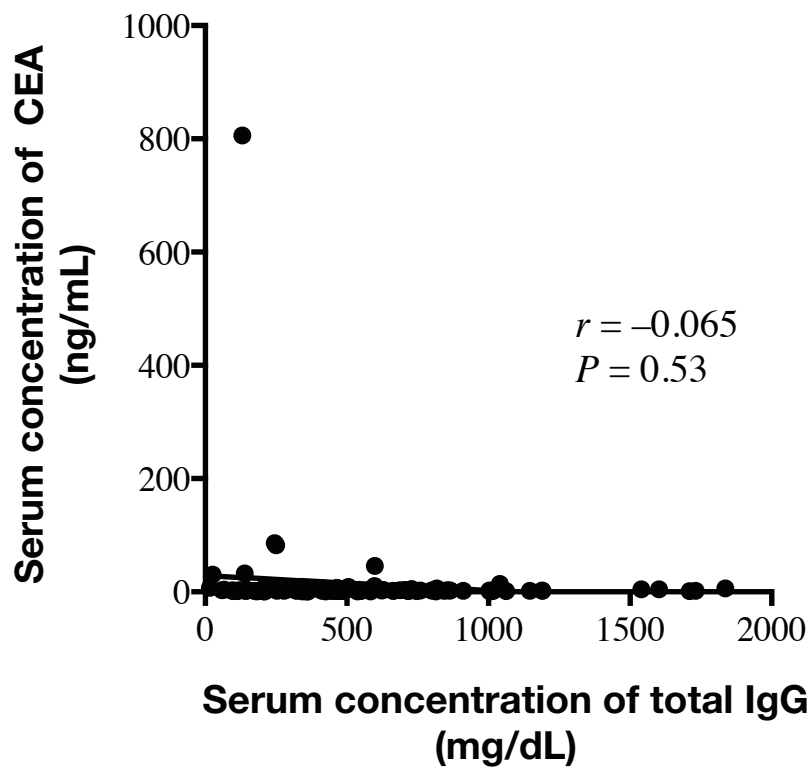

Fig. 2. Correlation between serum concentration of total IgG and CEA. There was no significant correlation between serum concentration of total IgG and CEA $(r=-0.065, P=0.53)$. IgG, Immunoglobulin $\mathrm{G}$; CEA, carcinoembryonic antigen.

cancer patients compared with control patients, although the differences were not statistically significant. These results indicate that antibody-mediated immunity is impaired in the patients with gastric cancer. This impairment seems to be dependent on the level of tumor burden as lower serum concentrations of IgG were related to the presence of lymph node metastasis and an advanced stage of disease. An important finding is that a decrease in the serum concentration of $\operatorname{IgG}$ was closely correlated to the poor prognosis of gastric cancer patients. In this regard, Jerome et al. have described a long-term survivor of breast cancer whose tumor strongly expressed mucin-1 (MUC-1); a transmembrane glycoprotein that results in circulating anti-mucin antibodies of both the $\operatorname{IgM}$ and $\operatorname{IgG}$ isotypes. These antibodies are not found in control patients, which indicated that the level of the patient's anti-mucin immunity may have helped protect her against recurrent tumor. ${ }^{20}$ Furthermore, Coronella et al. have demonstrated that an in situ antigen-driven oligoclonal B cell responded to a variety of tumor- and breast-associated antigens. ${ }^{21}$ These studies clearly indicate that an antibody-mediated immune response is also important in tumor immunity. Therefore, the correlation between the serum concentration of $\operatorname{IgG}$ and the prognosis of gastric cancer patients observed in the current study may be due to impairment of antibody-mediated immunity. Among four subclasses of $\mathrm{IgG}$, on the other hand, IgG1 seems to play the most important roles in tu- 
mor immunity, because a significant difference in prognosis was observed only in IgG1. In this regard, IgG1 is capable of eliciting antibody-dependent cell-mediated cytotoxicity, antibody-dependent cellular phagocytosis, and complement-dependent cytotoxicity. Because IgG1 is normally the most abundant subclass of all the $\mathrm{IgGs}$, a lack of IgG1, which is observed in a variety of primary and secondary antibody deficiencies, can result in a decrease of total IgG. An IgG1 deficiency, and sometimes in combination with other IgG subclass deficiencies, is associated with recurrent infections..$^{22}$ Therefore, in the current study it was likely that the low levels of IgG1 indicated impaired antibody-mediated immunity in the gastric cancer patients.

Because plasma cells are the only cells that can produce $\mathrm{IgG}$, we measured the number of plasma cells in non-cancerous gastric mucosa and in the gastric cancer tissue by immunohistochemistry using the anti-CD138 antibody. From this we sought to determine the detailed mechanisms responsible for the decreased serum concentration of IgG. The number of CD138-positive plasma cells was significantly lower in the gastric cancer tissue compared with non-cancerous gastric mucosa. Therefore, a decrease in CD138-positive plasma cells in the gastric cancer tissue may be correlated with a decrease in the serum concentration of IgG. Unfortunately, the detailed mechanisms responsible for the decrease in the number of CD138-positive plasma cells in the gastric cancer tissue remain unclear; further investigation is required.

It is easy to measure the serum concentration of IgG. The serum concentration of total IgG is significantly related to the prognosis of gastric cancer patients. Furthermore, multivariate analysis indicated that the serum concentration of total $\mathrm{IgG}$ was an independent prognostic indicator for poorer survival. Therefore, the serum concentration of total IgG can be used as a prognostic indicator. In this regard, CEA is usually used routinely in the clinic and it has already been demonstrated that CEA is closely related to the prognosis of gastric cancer patients. ${ }^{23}$ Our results indicate that there was no statistical correlation between the serum concentration of CEA and total $\mathrm{IgG}$, indicating that the serum concentration of total IgG may be useful as a prognostic indicator, regardless of the serum concentration of CEA. The close correlation between the decreased serum concentration of IgG and poor patient prognosis suggests that antibody-mediated immunity may be a target for the treatment of gastric cancer. Moreover, the serum concentration of IgG may be useful in predicting tumor recurrence and patient prognosis; however, to confirm both of these hypotheses, additional studies are needed.
To our knowledge, this study is the first to show that the serum concentration of $\mathrm{IgG}$ is decreased in gastric cancer tissue and is associated with a poor prognosis for gastric cancer patients. Impaired antibody-mediated immunity may be one of the main mechanisms responsible for the progression of gastric cancer and a better understanding of these mechanisms may lead to novel treatments.

\section{The authors declare no conflicts of interest.}

Human rights statement and informed consent: All procedures followed were in accordance with the ethical standards of the responsible committee on human experimentation (institutional and national) and with the Helsinki Declaration of 1964 and later versions. Informed consent or substitute for it was obtained from all patients for being included in the study.

\section{REFERENCES}

1 Hodi FS, O'Day SJ, McDermott DF, Weber RW, Sosman JA, Haanen JB, et al. Improved survival with ipilimumab in patients with metastatic melanoma. N Engl J Med. 2010;363:71123. PMID: 20525992.

2 Brahmer J, Reckamp KL, Baas P, Crino L, Eberhardt WE, Poddubskaya E, et al. Nivolumab versus Docetaxel in Advanced Squamous-Cell Non-Small-Cell Lung Cancer. N Engl J Med. 2015;373:123-35. PMID: 26028407.

3 Postow MA, Chesney J, Pavlick AC, Robert C, Grossmann K, McDermott D, et al. Nivolumab and ipilimumab versus ipilimumab in untreated melanoma. N Engl J Med. 2015;372:200617. PMID: 25891304.

4 Landskron G, De la Fuente M, Thuwajit P, Thuwajit C, Hermoso MA. Chronic inflammation and cytokines in the tumor microenvironment. J Immunol Res. 2014;2014:149185. PMID: 24901008.

5 Fourcade J, Sun Z, Benallaoua M, Guillaume P, Luescher IF, Sander C, et al. Upregulation of Tim-3 and PD-1 expression is associated with tumor antigen-specific CD8+ T cell dysfunction in melanoma patients. J Exp Med. 2010;207:2175-86. PMID: 20819923.

6 Matsuzaki J, Gnjatic S, Mhawech-Fauceglia P, Beck A, Miller A, Tsuji T, et al. Tumor-infiltrating NY-ESO-1-specific CD8+ T cells are negatively regulated by LAG- 3 and PD- 1 in human ovarian cancer. Proc Natl Acad Sci U S A. 2010;107:7875-80. PMID: 20385810.

7 Sakaguchi S, Yamaguchi T, Nomura T, Ono M. Regulatory T cells and immune tolerance. Cell. 2008;133:775-87. PMID: 18510923.

8 Wing K, Sakaguchi S. Regulatory T cells exert checks and balances on self tolerance and autoimmunity. Nat Immunol. 2010;11:7-13. PMID: 20016504.

9 Curiel TJ, Coukos G, Zou L, Alvarez X, Cheng P, Mottram $\mathrm{P}$, et al. Specific recruitment of regulatory $\mathrm{T}$ cells in ovarian carcinoma fosters immune privilege and predicts reduced survival. Nat Med. 2004;10:942-9. PMID: 15322536.

10 Perrone G, Ruffini PA, Catalano V, Spino C, Santini D, Muretto $\mathrm{P}$, et al. Intratumoural FOXP3-positive regulatory $\mathrm{T}$ cells are associated with adverse prognosis in radically resected gastric cancer. Eur J Cancer. 2008;44:1875-82. PMID: 
18617393

11 Bates GJ, Fox SB, Han C, Leek RD, Garcia JF, Harris AL, et al. Quantification of regulatory $\mathrm{T}$ cells enables the identification of high-risk breast cancer patients and those at risk of late relapse. J Clin Oncol. 2006;24:5373-80. PMID: 17135638.

12 Papadea C, Check IJ. Human immunoglobulin G and immunoglobulin $\mathrm{G}$ subclasses: biochemical, genetic, and clinical aspects. Crit Rev Clin Lab Sci. 1989;27:27-58. PMID: 2647414.

13 French M. Serum IgG subclasses in normal adults. Monogr Allergy. 1986;19:100-7. PMID: 3762537.

14 Steplewski Z, Sun LK, Shearman CW, Ghrayeb J, Daddona P, Koprowski H. Biological activity of human-mouse IgG1, IgG2, IgG3, and IgG4 chimeric monoclonal antibodies with antitumor specificity. Proceedings of the National Academy of Sciences of the United States of America. 1988;85:4852-6. PMID: 3387441.

15 Yamaguchi H, Furukawa K, Fortunato SR, Livingston PO, Lloyd KO, Oettgen HF, et al. Cell-surface antigens of melanoma recognized by human monoclonal antibodies. Proceedings of the National Academy of Sciences of the United States of America. 1987;84:2416-20. PMID: 3031684.

16 Jemal A, Bray F, Center MM, Ferlay J, Ward E, Forman D. Global cancer statistics. CA Cancer J Clin. 2011;61:69-90. PMID: 21296855.

17 Inoue H, Mori M, Honda M, Li J, Shibuta K, Mimori K, et al. The expression of tumor-rejection antigen "MAGE" genes in human gastric carcinoma. Gastroenterology. 1995;109:1522-5. PMID: 7557134.
18 Hoshino T, Seki N, Kikuchi M, Kuramoto T, Iwamoto O, Kodama I, et al. HLA class-I-restricted and tumor-specific CTL in tumor-infiltrating lymphocytes of patients with gastric cancer. International journal of cancer. 1997;70:631-8. PMID: 9096641.

19 Japanese Gastric Cancer Association. Japanese classification of gastric carcinoma: 3rd English edition. Gastric cancer : official journal of the International Gastric Cancer Association and the Japanese Gastric Cancer Association. 2011;14:101-12. PMID: 21573743.

20 Jerome KR, Kirk AD, Pecher G, Ferguson WW, Finn OJ. A survivor of breast cancer with immunity to MUC-1 mucin, and lactational mastitis. Cancer immunology, immunotherapy : CII. 1997;43:355-60. PMID: 9067407.

21 Coronella JA, Spier C, Welch M, Trevor KT, Stopeck AT, Villar H, et al. Antigen-driven oligoclonal expansion of tumor-infiltrating B cells in infiltrating ductal carcinoma of the breast. Journal of immunology (Baltimore, Md : 1950). 2002;169:1829-36. PMID: 12165506.

22 Jefferis R, Kumararatne DS. Selective IgG subclass deficiency: quantification and clinical relevance. Clinical and experimental immunology. 1990;81:357-67. PMID: 2204502.

23 Shimada H, Noie T, Ohashi M, Oba K, Takahashi Y. Clinical significance of serum tumor markers for gastric cancer: a systematic review of literature by the Task Force of the Japanese Gastric Cancer Association. Gastric cancer : official journal of the International Gastric Cancer Association and the Japanese Gastric Cancer Association. 2014;17:26-33. PMID: 23572188. 